\title{
KANDUNGAN BAHAN KIMIA OBAT PADA OBAT TRADISIONAL YANG BEREDAR DI PASARAN
}

\author{
Putu Larassita Abdi Pertiwi*, Ni Luh Putu Suariyani \\ Program Studi Kesehatan Masyarakat Fakultas Kedokteran Universitas Udayana \\ ${ }^{*}$ E-mail: larassitaa@gmail.com
}

\begin{abstract}
ABSTRAK
Obat tradisional seperti jamu masih banyak digunakan oleh masyarakat Indonesia, banyaknya jenis obat tradisional yang saat ini muncul di pasaran. Tahun 2018 terdapat 135 industri obat di Indonesia. Dengan banyaknya obat tradisional yang beredar menyebabkan sulitnya melakukan pengontrolan industri obat tradisional yang tidak menerapkan CPOTB (Cara Pembuatan Obat Tradisional yang Baik) dalam proses produksi obat tradisional. Adapun tujuan penelitian ini adalah untuk mengetahui bagaimana gambaran penggunaan bahan kimia obat pada berbagai produk obat tradisional. Metode pengumpulan data yang digunakan yaitu dengan pengumpulan data sekunder. Dengan menggunakan teknik analisis data univariate. Hasil : Berdasarkan hasil analisis data ditemukan bahwa telah adanya penurunan obat tradisional dengan bahan kimia obat. Kandungan bahan kimia terbanyak ditemukan pada obat tradisional yang berkhasiat Jamu Stamina Pria. Bahan kimia obat yang masih banyak ditemukan yakni : Sildenafil Sitrat, Paracetamol, Dexamethason, CTM, Na Diklofenak, Fenibutason, Piroksikam, Sibutramin HCL. Penurunan penggunaan obat tradisional dengan bahan kimia obat dapat bukan berarti tidak ada obat tradisional yang menggunakan bahan kimia obat. Hal ini disebabkan karena masih banyak masyarakat yang tertarik dengan efek yang lebih cepat yang diberikan. Namun, masyarakat tidak tahu bahwa obat yang dikonsumsi tersebut apabila di konsumsi secara terus menerus akan memberikan efek yang berbahaya bagi tubuh.
\end{abstract}

Kata kunci : BPOM, Bahan Kimia Obat, Obat Tradisional

\begin{abstract}
Traditional medicine such as herbal medicine is still widely used in Indonesia, there are many types of traditional medicine that currently appear on the market. In 2018 there are 135 drug industries in Indonesia. Many traditional medicine in market, it makes difficult to control the traditional medicine industry that does not apply CPOTB (Good Manufacturing Practices of Traditional Medicine) in the production process of traditional medicines. The purpose of this research is to find out how the description of the use of medicinal chemicals in various traditional medicinal products. Data collection method used is by collecting secondary data. By using univariate data analysis techniques. Results: Based on the results of data analysis it was found that there had been a decline in traditional medicine with medicinal chemicals. The highest content of chemicals is found in traditional medicines that have the efficacy of Male Stamina Herbs. Many medicinal chemicals that are still found are: Sildenafil Citrate, Paracetamol, Dexamethason, CTM, Na Diclofenac, Fenibutason, Piroxikam, Sibutramin HCL. Decreasing the use of traditional medicines with medicinal chemicals it's mean there are still traditional medicines that use medicinal chemicals by traditional medicine There are still many people who are interested in the faster effects that are given. By traditional medicine, will have a harmful effect on the body. Therefore, it a chance for the industrial to ad medicine chemical into their traditional medicine. However, commounity do not have enough knowledge that consume that kind of medicine continously.
\end{abstract}

Keywords: BPOM, Drug Chemicals, Traditional Medicine

\section{PENDAHULUAN}

Obat Tradisional merupakan salah satu jenis pengobatan yang masih banyak dipercaya dan digunakan oleh masyarakat yang ada di Indonesia. Penggunaan obat tradisional di kalangan masyakat ini 
diturunkan dari leluhur dengan menggunakan bahan-bahan alam yang sudah ada. Pengobatan menggunakan obat tradisional ini dimanfaatkan oleh masyarakat sebagai pengobatan sendiri dengan menggunakan bahan-bahan alam yang diracik menjadi obat tradisional sebagai jamu/boreh atau balsam yang digunakan untuk menghangatkan badan.

Pada era ini produk-produk obat tradisional yag beredar dikalangan masyarakat. Produk-produk obat tersebut sudah terkemas secara rapi, modern serta sudah mudah didapatkan oleh masyarakat. Produk-produk obat tradisional yang beredar di masyarakat dan melihat masyarakat yang tertarik untuk menggunakan obat-obatan tradisional tersebut semakin banyak pula perkembangan dari obat-obat tradisional yang ada. Banyak produsen-produsen obat tradisional yang muncul karena melihat pangsa pasar dari obat tradisional yang cukup baik. Melihat persaingan dari pangsa pasar dari obat tradisional ini banyak produsen obat-obatan tradisional yang tidak menerapkan CPOTB (Cara Pembuatan Obat Tradisional yang Baik).

Cara pembuatan Obat Tradisional yang Baik, yang selanjutnya disingkat CPOTB, adalah pedoman dasar dalam pembuatan obat tradisional yang menyangkut seluruh aspek produksi dan pengendalian mutu, yang bertujuan untuk menjamin agar produk obat tradisional yang dihasilkan senantiasa memenuhi persyaratan mutu yang ditetapkan sesuai dengan tujuan penggunaannya. (Hapsari,2014).

Penerapan СРОТВ ini bertujuan untuk menjamin mutu dari setiap produk obat tradisional. Penjaminan mutu ini juga memiliki tujuan untuk membebaskan obatobatan tradisional dari kandungan bahan yang bukan bahan alam yaitu bahan kimia.

Obat Tradisional adalah bahan atau ramuan bahan tanaman, bahan hewan, bahan mineral, sediaan sarian atau galenik dari bahan tersebut, yang secara turun temurun telah digunakan untuk pengobatan dan dapat diterapkan sesuai dengan norma yang berlaku di masyarakat (Ruli Setya Hapsari, S.Si., Apt Desi Rahayu Suwarguningriup, S.Farm. et al., 2014). Dengan Persaingan yang makin pesat banyak produsen obat tradisional yang mengingkan keuntungan yang lebih besar dengan menambahkan bahan kimia obat ke dalam produk obat tradisional yang dibuat. Penambahan bahan kimia obat ini memiliki tujuan agar meningkatnya khasiat dari obat tradisional agar memiliki efek lebih cepat daripada semestinya.(Balai Besar POM RI, 2010)

Pada tahun 2018 terdapat 135 industri obat tradisional yang tersebar di berbagai wilayah di Indonesia dengan sebaran terbanyak pada daerah Jawa Barat dengan 50 industri obat tradisional. Sedangkan di Bali sendiri terdapat beberapa industri obat tradisional. (Grafik Rekapitulasi IOT, Kemenkes RI). Di Bali sendiri terdapat beberapa industry obat tradisional seperti PT. Karya Pak Oles Tokcer yang memiliki kantor pusat di Jalan Komodo no. 38 X, DenpasarBali.

Adanya beberapa industri obat tradisional di Bali, peredaran obat-obatan tradisional yang bukan berasal dari industry obat tradisional yang ada di Bali masih terjadi. Obat-obatan tradisional yang berasal dari luar 
daerah bali juga ditemukan beredar di

Bali merupakan daerah wisata dimana walaupun hanya terdapat 1 pabrik obat tradisional namun masih banyak obat tradisional yang masuk ke Bali. Dengan masih banyaknya peredaran obat tradisional di Bali perlu adanya pengamatan terhadap obat tradisional yang mengandung bahan kimia obat didalamnya.

Maka dari itu peneliti tertarik untuk mengetahui bagaimana perkembangan obat tradisional yang ada di bali dengan melakukan penelitian ini untuk mengamati jumlah obat tradisional yang menggunakan bahan kimia obat.

Berdasarkan analisis risiko temuan pengawasan OT-BKO (Obat Tradisional dengan Kandungan Bahan Kimia Obat di dalamnya). Obat tradisional yang beredar pada semester pertama tahun 2010 masih ditemukan obat tradisional yang mengandung bahan kimia obat (BKO) yang dilarang dicampurkan ke dalam obat tradisional.(Lukito, 2010).

Pada analisis temuan OT-BKO dalam laporan pers BPOM RI selama 5 tahun terakhir, terjadi penurunan temuan OT yang mengandung $\mathrm{BKO}$ dari $1,65 \%$ menjadi $0,72 \%$ dari seluruh OT yang disampling dengan rincian, di 2007 sebanyak 1,65\%, 2008 sebanyak 1,27\%, 2009 sebanyak 1,06 \%, 2010 sebanayak $0,84 \%$ dan di 2011 sejumlah $0,72 \%$ obat tradisional yang mengandung bahan kimia obat.(Lukito, 2010).

Melihat masih adanya penambahan bahan kimia obat pada obat tradisional yang ditemukan oleh BBPOM, namum belum banyak data tentang penambahan bahan kimia obat yang ada pada obat tradisional data tersebut. Untuk itu peneliti tertarik untuk melihat bagaimana perkembangan gambaran obat tradisional dengan kandungan bahan kimia obat di dalamnya.

\section{METODE PENELITIAN}

Penelitian ini menggunakan data sekunder yaitu data sampel obat yang telah di ujikan di BBPOM di Denpasar. Populasi Target dari penelitian ini adalah seluruh produk obat tradisional yang ada di Provinsi Bali. Sedangkan populasi terjangkau dari penelitian ini adalah seluruh produk obat tradisional yang sudah di laukan pengujian di Balai Besar POM di Denpasar. Sampel dalam penelitian ini adalah seluruh populasi terjangkau yaitu seluruh produk obat tradisional yang telah mendapatkan prosedur pengujian pada Balai Besar POM di Denpasar.

Penelitian ini merupakan penelitian deskriptif kuantitatif dengan sampel yang bersifat homogen yang bertujuan untuk mengetahui gambaran pada obat tradisional yang memiliki kandungan bahan kimia obat di dalamnya dengan menggunakan jenis teknik pengambilan sampel obat tradisional yang sudah di uji di Balai Besar POM di Denpasar yakni Total Sampling.

Dengan Pengolahan data dengan teknik editing, coding dan proses pengolahan data. Penelitian ini menggunakan teknik analisis data univariat.

Analisis univariat adalah analisis yang digunakan untuk menjabarkan secara deskriptif variabel yang di teliti. Pada analisis ini akan diperoleh frekuensi dan persentase dari masing-masing variabel yang akan disajikan dalam bentuk grafik.

\section{HASIL}


Hasil penelitian ini menunjukkan bahwa telah terjadi penurunan jumlah produk obat tradisional yang menggunakan bahan kimia obat di dalamnya, jenis obat tradisional yang paling banyak menggunakan bahan kimia obat adalah jenis obat tradisional yang memiliki khasiat sebagai jamu stamina pria. Adapun jenis-jenis bahan kimia obat yang terdapat dalam produk-produk obat tradisional yang di uji di BBPOM adalah : Sildenafil Sitrat, Paracetamol, Dexamethason, CTM, Na Diklofenak, Fenibutason, Piroksikam, Sibutramin HCL.

Gambaran Produk Obat Tradisional di Provinsi Bali Pada Tahun 2015-2017 di Bali

Tabel 1 Sampel Obat Tradisional yang Diambil Oleh BBPOM di Denpasar Pada Tahun 20152017

\begin{tabular}{|c|c|c|c|c|}
\hline Kategori Sampel & 2015 & 2016 & 2017 & Total \\
\hline Balsam/Param & 30 & 30 & 48 & 108 \\
\hline Jamu Anti Alergi & 5 & & & 5 \\
\hline Jamu Anti Asma & 7 & 2 & 3 & 12 \\
\hline Jamu Anti Malaria & & 1 & & 1 \\
\hline Jamu Gangguan Perut & 15 & 8 & 6 & 29 \\
\hline Jamu Kencing Manis & 5 & 5 & 7 & 17 \\
\hline Jamu Keputihan & & 1 & & 1 \\
\hline Jamu Masuk Angin & & 1 & & 1 \\
\hline Jamu Pegal Linu & 136 & 142 & 121 & 399 \\
\hline Jamu Pelancar Air Seni & 8 & 11 & 14 & 33 \\
\hline Jamu Pelangsing & 71 & 81 & 70 & 222 \\
\hline Jamu Penambah Nafsu Makan & 39 & 40 & 38 & 117 \\
\hline Jamu Sehat Wanita & 36 & 33 & 27 & 96 \\
\hline Jamu Stamina Pria & 133 & 110 & 146 & 389 \\
\hline Jamu Tekanan Darah Tinggi & 9 & 4 & & 13 \\
\hline Jamu Wasir & 2 & 5 & 3 & 10 \\
\hline Obat Penenang/Anti Gelisah & 1 & 1 & & 2 \\
\hline Obat Sariawan & & 1 & 1 & 2 \\
\hline Obat Flu/Demam/Batuk/Sakit Kepala & 58 & 63 & 62 & 183 \\
\hline Obat Gatal - Gatal & & 1 & 13 & 14 \\
\hline Obat Sariawan & 7 & 6 & 5 & 18 \\
\hline Pelancar Air Seni - serbuk & & & 1 & 1 \\
\hline Pil Sakit Gigi & 2 & & & 2 \\
\hline Total & 564 & 546 & 565 & 1675 \\
\hline
\end{tabular}




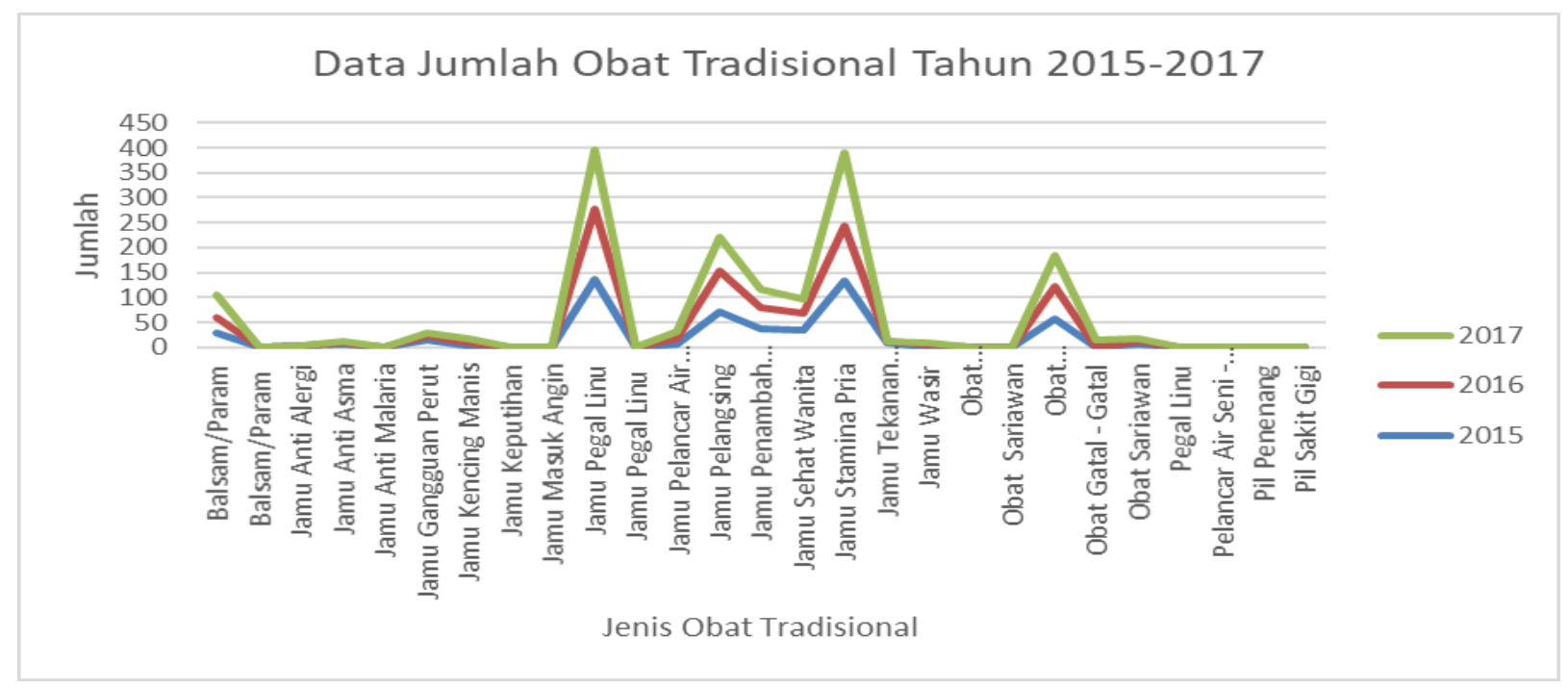

Gambar 1 Grafik Jumlah Sampel Obat Tradisional Dari BBPOM di Denpasar Tahun 20152017

Berdasarkan grafik diatas didapatkan bahwa beberapa jenis obat tradisional yang diperiksa di Balai Besar POM, Obat tradisional yang paling banyak digunakan pada tahun 2015-2017 adalah jamu pegal linu, jamu stamina pria dan jamu pelangsing dan sedangkan yang paling sedikit digunakan adalah jenis obat tradisonal yang berkhasiat sebagai obat penenang dan gelisah dan pil sakit gigi. Penggunaan obat tradisional yang berkhasiat sebagai balsam/param di tahun 2017. Pada tahun 2017 obat tradisional yang berkhasiat sebagai jamu pegal linu mengalami penurunan dalam pemeriksaan oleh BBPOM.

Selanjutnya pada obat tradisional yang berkhasiat sebagai jamu pelancar air seni mengalami peningkatan jumlah obat tradisional yang diperiksa oleh BBPOM dari tahun 2015-2017.

Obat Tradisional Yang Mengandung Bahan Kimia Obat Pada Tahun 2015-2017

Tabel 2 Obat Tradisional Yang Menggunakan Bahan Kimia Obat dari BBPOM di Denpasar

\begin{tabular}{lcccc}
\hline \multicolumn{1}{c}{ Kategori Sampel } & $\mathbf{2 0 1 5}$ & $\mathbf{2 0 1 6}$ & $\mathbf{2 0 1 7}$ & Total \\
\hline Balsam/Param & & & 1 & 1 \\
Jamu Gangguan Perut & 2 & & & 2 \\
Jamu Pegal Linu & 7 & & & 7 \\
Jamu Pelangsing & 2 & 2 & 4 \\
Jamu Penambah Nafsu Makan & 1 & & & 1 \\
Jamu Sehat Wanita & 4 & 2 & 4 & 10 \\
Jamu Stamina Pria & 34 & 19 & 18 & 71 \\
Obat Flu/Demam/Batuk/Sakit Kepala & 3 & 2 & & 5 \\
& 99 & & &
\end{tabular}




\begin{tabular}{lcccc} 
Obat Gatal - Gatal & & 1 & 1 \\
Obat Sariawan & 1 & & 1 \\
Pil Sakit Gigi & 2 & & & 2 \\
\hline Total & $\mathbf{5 6}$ & $\mathbf{2 3}$ & $\mathbf{2 6}$ & $\mathbf{1 0 5}$
\end{tabular}

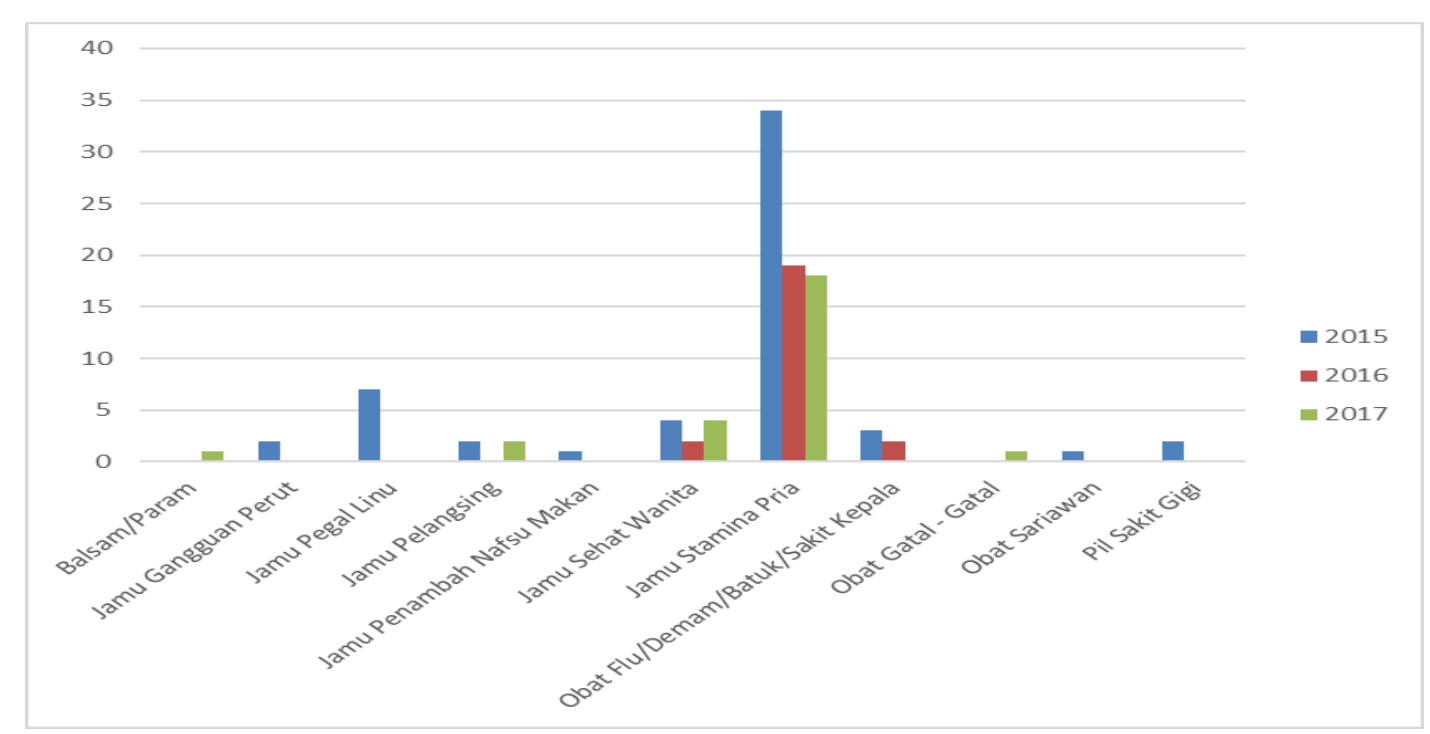

\section{Gambar 2 Gambaran Obat Tradisional Yang Mengandung Bahan Kimia Obat Tahun 2015- 2017}

Berdasarkan grafik yang terdapat diatas, setelah dilakukan pemeriksaan pada sampel obat tradisional di BBPOM di Denpasar yang mengandung bahan kimia obat dari tahun 2015-2017 adalah obat tradisional yang berkhasiat Jamu Stamina Pria. Dan obat tradisional yang diperiksa oleh BBPOM yang ditemukan menggunakan bahan kimia obat paling sedikit adalah obat tradisional yang berkhasiat sebagai balsam/param, obat gatal- gatal dan obat sariawan. Pada Jamu Stamina Pria terjadi penurunan jumlah produk obat tradisional dengan kandungan bahan kimia obat dari tahun 2015-2017.

Sedangkan pada Jamu Sehat Wanita pada tahun 2016 mengalami penurunan dan pada tahun 2017 mengalami kenaikan jumlah obat tradisional dengan kandungan bahan kimia obat yang diperiksa oleh BBPOM. 
Arc. Com. Health • Desember 2020

p-ISSN 2302-139X e-ISSN 2527-3620

Vol. 7 No. 2 : 95 - 106

Jenis Bahan Kimia Obat Yang Terkandung Pada Obat Tradisional Yang Telah Diperiksa Oleh BBPOM di Denpasar

Tabel 3 Bahan Kimia Obat Yang Ada Pada Obat Tradisional

\begin{tabular}{lll}
\hline No. & Kategori Sampel Kahan Kimat
\end{tabular}

1. Jamu Stamina Pria

2. Obat Batuk, Demam, Pilek dan Sakit Kepala

3. Jamu Pegal Linu
Sildenafil sitrat

Parasetamol, Dexamethason, CTM

Natrium Diklofenak, Paracetamol, Fenilbutazon, Piroksikam

Parasetamol

5. Jamu Pelangsing

Sibutramin HCL

Berdasarkan tabel diatas telah didapatkan beberapa bahan kimia obat yang telah diperiksa oleh BBPOM yang ditemukan dalam beberapa produk obat tradisional yang beredar di masyarakat. Jenis bahan kimia obat yang ditemukan oleh BPOM seperti paracetamol yang ditemukan pada jenis obat tradisional yang berkhasiat sebagai Obat Batuk, Pilek, dan Demam Sakit Kepala, Jamu Pegal Linu dan pada Pil Sakit Gigi. Paracetamol ini adalah bahan kimia obat yang

\section{DISKUSI}

\section{Gambaran Produk Obat Tradisional di Provinsi Bali Pada Tahun 2015-2017 di Bali}

Obat Tradisional adalah salah satu kekayaan yang dimiliki oleh masyarakat Indonesia, Di Indonesia sendiri masih banyak masyarakat yang memanfaatkan obat tradisional dibandingkan dengan penggunaan obat-obatan kimia. Pemeriksaan obat tradisional yang berkhasiat sebagai analgteik-antipiretik dalam bentuk sediaan tunggal. Selanjutnya pada Jamu Stamina Pria ditemukan bahan kimia obat Sildenafil Sitrat dan Coffein. Sildenafil Sitrat sendiri memiliki khasiat untuk mengatasi disfungsi seksual pada pria. Pada Jamu pelangsing ditemukan jenis bahan kimia obat yaitu Sibutramin HCL yang merupakan salah satu bahan kimia obat yang memiliki khasiat sebagai antiobesitas dilakukan oleh BBPOM di Denpasar setiap tahunnya. Pada tahun 2015 sampel obat tradisional yang diperiksa oleh BBPOM di Denpasar sejumlah 564 sampel, tahun 2016 sebanyak 546 sampel dan pada tahun 2017 sebanyak 565 sampel obat tradisional. Dari jumlah total 
1675 sampel obat tradisional yang diperiksa oleh BBPOM dalam 3 tahun terakhir obat tradisional yang paling banyak digunakan di kalangan masyarakat adalah jenis obat tradisional yang memiliki khasiat sebagai : Jamu Pegal Linu, Jamu Stamina Pria dan Jamu Pelangsing. Sedangkan produk obat tradisional yang paling sedikit digunakan oleh masyarakat adalah produk-produk obat tradisional seperti obat penenang dan pil sakit gigi.(Lathif, 2013)

Melihat cukup tingginya konsumsi obat tradisional dimasyarakat, masih banyak produk-produk obat tradisional tersebut yang menggunakan bahan kimia obat di dalamnya, agar produk obat yang di hasilkan memberikan efek yang lebih cepat daripada semestinya. Efek yang diinginkan lebih cepat dicapai menyebabkan banyak masyarakat masih percaya dengan produk obat tradisional karena efeknya cepat dicapai tetapi tidak tahu bahwa di dalam obat tradisional tersebut berisi bahan kimia obat yang sebenarnya memiliki efek yang berbahaya apabila dikonsumsi secara terus-menerus dengan dosis yang tidak tepat.

Obat Tradisional Yang Mengandung Bahan Kimia Obat Pada Tahun 2015-2017

Penggunaan bahan kimia obat dalam obat tradisional masih cukup banyak dilakukan, beberapa produk seperti produk-produk jamu pegal linu, jamu pelangsing dan jamu stamina pria masih banyak ditemukan bahan kimia di dalam produknya. Penggunaan bahan kimia obat dengan dosis yang tidak tepat ini dapat memberikan efek yang tidak baik untuk tubuh apabila digunakan secara terus-menerus. (Ishaq, 2015)
Pada pemeriksaan oleh BBPOM di Denpasar dari tahun 2015-2017 ditemukan beberapa jenis obat tradisional dengan kandungan bahan kimia obat masih beredar di masyarakat. Dari jumlah 1675 obat tradisional yang diperiksa dalam 3 tahun terakhir telah tejadi penurunan beberapa obat tradisional yang mengandung bahan kimia obat di dalamnya.

Pada hasil pemeriksaan BBPOM di Denpasar ditemukan bahwa obat tradisional dengan khasiat sebagai Jamu Stamina Pria yang paling banyak mengandung bahan kimia obat dengan jumlah 71 sampel selama 3 tahun terakhir, diikuti dengan jamu sehat wanita dengan jumlah 10 sampel. Pada jamu sehat wanita ini mengalami kenaikan jumlah produk yang menggunakan bahan kimia obat di dalamnya pada tahun 2017 yang sebelumnya pada tahun 2016 mengalami penurunan.

Dari pemeriksaan BBPOM di Denpasar ditemukan bahwa sampel obat tradisional yang menggunakan bahan kimia obat paling banyak adalah jamu dengan khasiat untuk stamina pria dan yang paling sedikit adalah obat tradisional yang memiliki khasiat sebagai balsam/param, obat gatal-gatal dan obat sariawan dengan jumlah masing-masing 1 sampel

Jenis Bahan Kimia Obat Yang Terkandung Pada Obat Tradisional Yang Telah Diperiksa Oleh BBPOM di Denpasar

Penggunaan obat tradisional yang salah adalah saat masyarakat memiliki ekspektasi bahwa obat tradisional dapat menyembuhkan, sehingga penggunaannya meningkat. Bagi masyarakat, obat tradisional yang bagus adalah yang memberikan reaksi 
cepat terhadap penyakit yang diderita dengan harga yang terjangkau. Obat tradisional sebenenarnya membutuhkan waktu yang lebih lama untuk memberikan efek kerja dibandingkan obat kimia. Namun sering kali masyarakat menginginkan obat tradisional yang memiliki efek yang lebih cepat. Padahal obat tradisional yang digunakan dalam sekali pakai telah memeberikan efek yang signifikan maka perlu diwaspadai kemungkinan ditambahkan bahan kimia obat (BKO).

Dengan perkembangan obat tradisional yang sangat pesat di seluruh dunia masyarakat sebaiknya mengetahui tentang toksisitas dan hasil interaksi dari toksisitas setiap obat tradisional yang beredar. Dari peredaran obat tradisional tersebut perlu adanya jaminan keamanan, kemanjuran efek obat dan quality control dari setiap obat yang diedarkan. Sehingga perlu adanya pengawasan yang komperhensif dimulai dari pengawasan bahan baku, proses produksi, proses pengemasan dan proses pemasaran dari produk obat tradisional tersebut. Dalam kaitan pengawasan ini Balai Besar POM telah mengeluarkan ketentuan cara pembuatan obat tradisional yang baik yang selanjutnya di sebut СРОTB pada tahun 2005 yang telah diperbaharui pada tahun 2011. Pelaksanaan СРОTВ ini belum maksimal dilaksanankan oleh setiap produsen obat-obatan tradisional yang ada, masih ada beberapa produsen obat tradisional yang tidak melaksanakan prosedur CPOTB dengan baik. Oleh karena itu masih cukup banyak ditemukan produk obat tradisional yang mengandung bahan kimia obat di dalamnya.(BPOM RI, 2019)

СРОТВ (Cara Pembuatan Obat Tradisional yang Baik) merupakan bagian dari jaminan mutu yang memastikan produk obat tradisional dibuat dan dikendalikan secara konsisten untuk mencapai standar mutu yang sesuai dengan tujuan penggunaan dan dipersyaratkan dalam izin edar serta spesifikasi produk (BPOM,2011).

Selain itu pemerintah juga membuat regulasi terkait syarat produsen obat tradisional. Hal ini bertujuan untuk memberikan iklim usaha yang kondusif bagi produsen obat tradisional. Berdasarkan kewenangannya untuk memproduksi obat tradisional, industri obat tradisional dikelompokkan menjadi 6, yaitu: Industri Obat tradisional, Industri Ekstrak Bahan Alam, Usaha Kecil Obat Tradisional, Usaha Mikro Obat Tradisional, Usaha Jamu Racikan dan Usaha Jamu Gendong (Permenkes,2012). (Rofida Siti, 2014)

Obat Tradisional adalah bahan atau ramuan bahan tanaman, bahan hewan, bahan mineral, sediaan sarian atau galenik dari bahan tersebut, yang secara turun temurun telah digunakan untuk pengobatan dan dapat diterapkan sesuai dengan norma yang berlaku di masyarakat.(Ruli Setya Hapsari, S.Si., Apt Desi Rahayu Suwarguningriup, S.Farm. et al., 2014)

Penambahan bahan kimia obat masih sering dilakukan oleh produsen obat tradisional guna memberikan efek lebih cepat dari semestinya. Efek yang lebih cepat dihasilkan akan menarik daya beli masyarakat yang mengonsumsi obat tersebut karena obat tersebut memberikan efek yang diingingkan lebih cepat. Akan tetapi masyarakat tidak mengetahui bahaya dari konsumsi bahan kimia obat apabila dikonsumsi dengan waktu lama dan dengan 
dosis yang kurang tepat.

Beberapa jenis obat tradisional yang telah di temukan berisikan bahan kimia obat adalah jenis obat tradisional seperti : Jamu Stamina Pria, Jamu Pelangsing, Jamu Pegal Linu, Obat Demam, batuk, pilek dan sakit kepala, Pil Sakit Gigi. Dari jenis-jenis obat tradisional yang di temukan berisi bahan kimia obat ini kandungan bahan kimia obat yang ditemukan antara lain adalah : Sildenafil Sitrat, Coffein Parasetamol, Dexamethason, CTM (Chlorpeneramine Maleat), Natrium Diklofenak, Fenilbutason dan Piroksikam.

Pada Jamu Stamina Pria banyak ditemukan sampel dengan kandungan sildenafil sitrat, Sildenafil sitrat merupakan obat yang digunakan untuk mengatasi disfungsi seksual.

Efek samping yang muncul dari penggunaan sildenafil sitrat yaitu sakit kepala, gangguan pencernaan, gangguan penglihatan, dyspepsia, rhinitis, infark miokard, nyeri dada, palpitasi dan kematian. Obat ini termasuk dalam kategori obat keras, sehingga penggunaan obat ini harus dengan resep dokter.(Rofida, 2012)

Sildenafil sitrat atau yang lebih dikenal dipasarkan di bawah nama merek dagang Viagra. obat ini banyak digunakan untuk menggunakan untuk penyakit yang berhubungan dengan disfungsi vaskuler yang sedang muncul. Apabila pengguna direkomendasikan obat, obat yang mengandung bahan obat ini memiliki kemanjuran klinis yang kuat dan profil yang aman dalam spektrum yang luas dari populasi pria.(Corbin and Francis, 2015).

Beberapa studi telah dilakukan dengan sildenafil pada pria dengan penyakit kardiovaskular. Data menunjukkan bahwa, dengan pengecualian pasien yang menggunakan nitrat organik, sildenafil tidak memiliki efek sinergis pada tekanan darah dengan agen antihipertensi, seperti ACE inhibitor, $\alpha$-adrenoceptor atau $\beta$-adrenoceptor blocker, calciumchannel blocker atau diuretics13.

Tidak ada peningkatan dalam kejadian efek samping terkait obat, dan profil keamanan keseluruhan menunjukkan bahwa tidak ada perbedaan yang signifikan dalam kejadian stroke, infark miokard atau kejadian kardiovaskular serius lainnya di pasien yang menggunakan sildenafil. Bahan kimia obat ini dapat meningkatkan fungsi ereksi pada hingga $70 \%$ pria dengan penyakit jantung iskemik, dan memberikan hasil yang serupa dalam uji coba dengan kelompok pria dengan penyakit kardiovaskular. (Rotella, 2012)

Sedangkan pada jamu untuk wanita kandungan bahan kimia obat yang ditemukan adalah Sibutramine HCL. Sibutramine adalah inhibitor reuptake serotonin dan norepinefrin yang telah menunjukkan kemanjuran sebagai agen penurunan berat badan dan pemeliharaan berat badan.(Ryan et al., 1995)

Sibutramin hidroklorida merupakan obat yang digunakan dalam terapi tambahan pada program penurunan berat badan. Penggunaan obat ini digunakan, jika upaya diet, olahraga, dan perubahan gaya hidup tidak berhasil. Efek samping yang muncul yaitu peningkatan denyut jantung, palpitasi (jantung berdebar), peningkatan tekanan darah, sakit kepala, kegelisahan, kehilangan nafsu makan, konstipasi, mulut kering, gangguan alat perasa, vasodilatsi, insomnia, dan pusing.(Sudewi and Lolo, 2017) 
Paracetamol merupakan obat yang digunakan untuk menghilangkan nyeri ringan sampai sedang. Penggunaan pasetamol dalam jangka panjang dapat menyebabkan gangguan kerusakan hati.

Efek samping yang muncul pada penggunaan metampiron menyebabkan gangguan saluran cerna seperti mual, perdarahan lambung, gangguan sistem syaraf, penghambat pembnetukan sel darah, dan gangguan ginjal.(Rofida, 2012).

Selain Sildenafil Sitrat, Sibutramin HCL dan Paracetamol, pada obat tradisional juga banyak ditemukan bahan kimia obat yaitu fenilbutason. Fenilbutason adalah obat Fenilbutazon adalah obat antiinflamasi nonsteroid (NSAID) yang bersifat asam, lipofilik, non-steroid. (Buff, 2018)

\section{SIMPULAN}

Adapun simpulan yang dapat diambil adalah :

Masih cukup banyak produsen obat tradisional tidak menerapkan СРОТВ pada proses produksi obat tradisional dengan menggunakan bahan kimia obat pada produk obat tradisional yang dibuat.

Jenis obat tradisional yang paling banyak berisi kan bahan kimia obat dan beredar di masyarakat adalah obat tradisional dengan khasiat sebagai stamina pria, pegal linu dan pelangsing.

Penggunaan bahan kimia obat ini dilakukan oleh produsen obat tradisional untuk meningkatkan daya beli masyarakat karena dengan menggunakan bahan kimia obat, obat tradisional yang di konsumsi akan menghasilkan efek yang lebih cepat dan signifikan daripada obat tradisional yang tidak menggunakan bahan kimia obat.
Kandungan bahan kimia obat dalam produk obat tradisional yang apabila dibandingkan dengan produk obat tradisional yang ada di masyarakat telah mengalami penurunan. Hanya 1 jenis obat yang mengalami peningkatan yaitu pada obat tradisional dengan khasiat sebagai jamu sehat wanita.

\section{SARAN}

Perlu adanya tindakan untuk monitoring terhadap pelaku usaha atau produsen obatobatan tradisional agar lebih menjaga mutu obat tradisional yang di produksi dan menerapkan CPOTB serta perlu adanya kegiatan promosi kesehatan bagi daerah yang merupakan tempat terbanyak ditemukan sampel dengan kandungan bahan kimia obat.

\section{DAFTAR PUSTAKA}

Balai Besar POM RI (2010) Penggunaan Bahan Kimia Obat Pada Obat Tradisional, Journal Of Pharmaceutical Health Care And Sciences.

BPOM RI (2019) Laporan Tahunan BPOM RI.

Buff, E. (2018) 'Phenylbutazone - My Investigation And Questions', American Farrier, 1(2), Pp. 36-42.

Corbin, J. D. And Francis, S. H. (2015) ‘Cyclic GMP Phosphodiesterase-5 : Target Of Sildenafil *, Pp. 13729-13733.

Ishaq, W. (2015) Perkembangan Obat Tradisional.

Lathif, A. (2013) Analisis Bahan Kimia Obat Dalam Jamu Pegal Linu Yang Dijual Di Surakarta Menggunakan Metode Spektrofotometri UV. Surakarta.

Rofida, S. (2012) 'Bahan Kimia Obat Pada Obat Tradisional Di Indonesia', Pp. 2010-2014.

Rotella, D. P. (2012) 'Phosphodiesterase 5 
Inhibitors : Current Status And Potential Applications', 1(September). Doi: 10.1038/Nrd893.

Ruli Setya Hapsari, S.Si., Apt Desi Rahayu Suwarguningriup, S.Farm., A. Et Al. (2014) Undang-Undang Kesehatan. Jakarta.
Ryan, D. H. Et Al. (1995) 'Sibutramine : A Novel New Agent For Obesity Treatment', 3, Pp. 3-9.

Sudewi, S. And Lolo, W. A. (2017) 'Pelangsing Yang Beredar Di Kota Manado', 6(4), pp. 75-81. 